\title{
What is the status of liver health in adults living with the Fontan circulation? Now that is a good question
}

\author{
Osman O. Al-Radi, MBBS, MSc, FRCSC
}

\footnotetext{
From the Department of Surgery, Abdullah Bakhsh Children's Heart Center, Faculty of Medicine, King Abdulaziz University, Jeddah, Saudi Arabia.

Disclosures: Author has nothing to disclose with regard to commercial support.

Received for publication Nov 1, 2016; accepted for publication Nov 2, 2016; available ahead of print Dec 17, 2016.

Address for reprints: Osman O. Al-Radi, MBBS, MSc, FRCSC, Department of Surgery, Abdullah Bakhsh Children's Heart Center, Faculty of Medicine, King Abdulaziz University, PO Box 80215, Bldg 10, Rm 1007, Jeddah 21589, Saudi Arabia (E-mail: oradi@kau.edu.sa).

J Thorac Cardiovasc Surg 2017;153:665-6

$0022-5223 / \$ 36.00$

Copyright (c) 2016 by The American Association for Thoracic Surgery

http://dx.doi.org/10.1016/j.jtcvs.2016.11.011
}

Voltaire, the French philosopher and deist, wrote in his notes: "Judge a man by his question rather than the meaning of his answer." Often the significance of a scientific work is in the importance and gravity of the question posed rather than the answers proposed. $\mathrm{Wu}$ and colleagues $^{1}$ from 6 large and old congenital heart surgery programs in the United States elegantly pose the question: "What is the health of the liver in patients who reach adulthood while living with the Fontan circulation." Although it may not be the first time this question was posed, ${ }^{2-4}$ it is done so now as a result of a monumental effort by 13 authors on behalf of the Alliance for Adult Research in Congenital Cardiology and certainly many more indirect contributors.

I have to admit that I never before considered this question with any degree of concern. So by the end of reading the article by $\mathrm{Wu}$ and colleagues ${ }^{1} \mathrm{I}$ was alarmed by the potentially heavy burden the answer to this seemingly simple question might pose for the already rapidly expanding problem of adults with palliated single-ventricle lesions. In 2016, Krasuski and Bashore, elegantly described the health care community's attitude toward the growing problem of adults with repaired congenital heart disease as "blindly feeling for the charging elephant." After reading the article by Wu and colleagues, it was as if the size of the euphemistic elephant had significantly increased.

$\mathrm{Wu}$ and colleagues ${ }^{1}$ sought to document the prevalence of liver disease and its associated factors in a large, diverse group of adult patients with Fontan physiology. Between 2009 and 2012, 241 adult patients who underwent the Fontan operation at some time in the past were enrolled in the study from 6 large and well-established centers in the United States with dedicated Adult Congenital Heart Surgery Programs. The median time since Fontan surgery was 20 years (range, 5 to 35 years). Each patient only underwent blood and imaging investigations that were deemed necessary by the managing team. Nonetheless, a

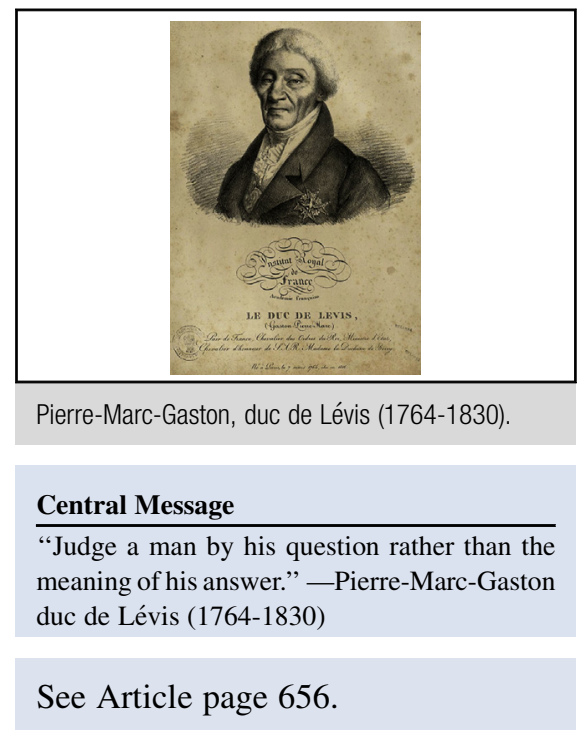

guideline-based protocol was provided to the centers. No doubt, the cohort represents some undescribed fraction of the total number of patients who underwent the Fontan operation at these 6 institutions over a period that potentially extends up to 35 years. The majority of tested patients, $94 \%$, had abnormal liver biochemical markers, and all of the patients who underwent imaging by magnetic resonance imaging or computed tomography had abnormalities on imaging consistent with variable degrees of hepatic fibrosis. All 68 patients who received liver biopsies also had a degree of liver fibrosis. Patients with abnormal lab values had higher degrees of fibrosis compared with patients with normal lab values, in tested patients. Disappointingly, no imaging studies correlated with the degree of fibrosis seen on histologic examination.

Prevalence is defined as the proportion of a given factor (disease or other attribute) found to be affecting a particular population of interest. ${ }^{6}$ It is usually expressed as a fraction or a percentage. Being certain of the denominator is, therefore, of obvious importance. Unfortunately, the analysis presented by $\mathrm{Wu}$ and colleagues ${ }^{1}$ is not sufficient to estimate the prevalence of liver fibrosis in adults with the Fontan circulation, according to this basic definition. Having said that, it might be becoming apparent why the quote often attributed to Voltaire becomes relevant to this discussion. The study by $\mathrm{Wu}$ and colleagues ${ }^{1}$ was an eye-opener for me despite my differences with its methodology for the mere importance of the question posed and the potential weight of the illusive answer. 
It turns out that Voltaire, whose real name was FrançoisMarie Arouet (1694-1778), never said or wrote this commonly misattributed statement. The actual writer was Pierre-Marc-Gaston, duc de Lévis (1764-1830). ${ }^{7}$

\section{References}

1. Wu FM, Kogon B, Earing MG, Aboulhosn JA, Broberg CS, John AS, et al. Liver health in adults with Fontan circulation: A multicenter cross-sectional study. $J$ Thorac Cardiovasc Surg. 2017;153:656-64.

2. Wu FM, Ukomadu C, Odze RD, Valente AM, Mayer JE Jr, Earing MG. Liver disease in the patient with Fontan circulation. Congenit Heart Dis. 2011;6:190-201.
3. Asrani SK, Warnes CA, Kamath PS. Hepatocellular carcinoma after the Fontan procedure. N Engl J Med. 2013;368:1756-7.

4. Ghaferi AA, Hutchins GM. Progression of liver pathology in patients undergoing the Fontan procedure: chronic passive congestion, cardiac cirrhosis, hepatic adenoma, and hepatocellular carcinoma. J Thorac Cardiovasc Surg. 2005;129: 1348-52.

5. Krasuski RA, Bashore TM. Congenital heart disease epidemiology in the United States: blindly feeling for the charging elephant. Circulation. 2016;134:110-3.

6. Rothman KJ. Epidemiology: an introduction. New York: Oxford University Press; 2012:53.

7. Maximes et réflexions sur différents sujets de morale et de politique. Paris: Maxim; 1808:xviii. 